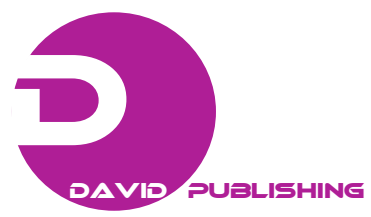

\title{
Food Consumption Patterns and Sustainable Natural Resources Management in the Mediterranean Region
}

\author{
Roberto Capone, Nicola Lamaddalena, Lamberto Lamberti, Abderraouf Elferchichi and Hamid El Bilali \\ Mediterranean Agronomic Institute of Bari (MAI-B), International Centre for Advanced Mediterranean Agronomic Studies \\ (CIHEAM), via Ceglie 9, 70010 Valenzano (Bari), Italy
}

Received: December 7, 2011 / Published: August 20, 2012.

\begin{abstract}
Sustainability of food systems and diets is not simply related to health concerns as it also involves environmental impacts. In fact, diets are major players in biodiversity erosion, natural resources degradation, climate change, etc.. The paper aims at analysing the main environmental impacts of the Mediterranean food consumption patterns on land and water resources and biodiversity. It provides a review on water and land resources and biodiversity in the Mediterranean and an analysis of the livestock sector impacts on ecosystem services. The most recent FAO food consumption statistics and standard impact data from different sources (e.g., Water Footprint Network; Mekonnen \& Hoekstra, 2010; Ewing et al., 2010) were used to calculate and discuss environmental impacts, i.e., water, carbon and ecological footprints. Mediterranean diets promote biodiversity use, conservation and sustainable natural resources management. They are more respectful of ecosystems and have lower environmental impacts than Northern Europe and American diets.
\end{abstract}

Key words: Mediterranean diets, environmental impacts, biodiversity.

\section{Introduction}

Modern agro-food systems failed to resolve the problem of hunger and malnutrition in the world. Moreover, they have also generated problems of overweight and obesity. Faced with fossil energy exhaustion, soil limited capacity, ecosystem degradation, climate change, unbalanced diets and population increase; the current food system can not be considered as sustainable and it is therefore necessary to act urgently to implement a strategy that promotes the use of the concept of "sustainable diets" in industrialized as well as developing countries. Diets are a significant factor in a number of critical sustainability issues such as climate change, public health, social inequality, biodiversity, energy, land and water use, etc. [1].

Sustainable diets are those with low environmental impacts which contribute to food and nutrition security

Corresponding author: Roberto Capone, researcher, research fields: sustainable consumption and production, mediterranean diet. E-mail: capone@iamb.it. and to healthy life for present and future generations. Sustainable diets are protective and respectful of biodiversity and ecosystems, culturally acceptable, accessible, economically fair and affordable; nutritionally adequate, safe and healthy; while optimizing natural and human resources [2]. They provide food that is produced locally and distributed in the markets, making it available, accessible and affordable, safe and nutritious to all, protecting the income of farmers and other workers, and consumer and communities' culture. Sustainable diets put nutrition, food and biodiversity at the core of sustainable development and human right to food.

Diets affect various dimensions (agricultural, food, nutritional, environmental, social, cultural, economic) that interact with one another, either inseparably or separately and distinctly. From this point of view, the Mediterranean is the area where more than any others should be addressed many issues (biodiversity loss, soil erosion, water scarcity, etc.) directly or indirectly related 
to Mediterranean food consumption patterns [3].

Healthy eating patterns reduce risks of diabetes and major coronary events. Such dietary patterns offer considerable health benefits to individuals and contribute to public health $[4,5]$. Many studies provided a strong evidence for a beneficial effect of higher conformity with the Mediterranean dietary pattern on risk of death from all causes, including cardiovascular diseases, and cancers [6, 7].

The recommended food pyramids do not offer only considerable health benefits but also respect the environment. In fact, the various food groups can be evaluated in terms of their environmental impact. Reclassifying foods no longer in terms of their positive impact on health, but on the basis of their negative effect on the environment, which produces an up-side-down pyramid which shows the foods with greater environmental impact on the top and those with lower impact on the bottom. When this new environmental pyramid is brought alongside the food pyramid, it creates a food-environmental pyramid called the "Double Pyramid". It shows that those foods with higher recommended consumption levels are also those with lower environmental impact. This unified model shows that if the diet suggested in the traditional food pyramid is followed, not only people do live better, but there is a decidedly less impact or better footprint left on the environment [8]. Therefore, human beings, through eating responsibly, can definitely reconcile their personal well-being (personal ecology) with the environment (ecological context) [8].

In the 1970s, the American physiologist, Ancel Keys, explained to the world the diet he dubbed "Mediterranean" based on balanced consumption of natural foods (olive oil, fruit, grains, legumes, etc.), thanks to which death rates from heart disease were shown to be lower than with diets typical of Northern Europe [9]. Naska [10] defined nine components of Mediterranean diet: high consumption of olive oil and low consumption of lipids of animal origin; high consumption of vegetables, legumes, cereals, and fruit; moderate to high consumption of fish; low to moderate consumption of milk and dairy products; low consumption of meat and meat products; and moderate wine consumption. Olive oil has been used throughout millennia by numerous Mediterranean civilizations. Olive oil is for Mediterranean peoples more than a mere food as it has also medicinal uses and is a source of fascination and wonder [11].

In order to be considered sustainable, Mediterranean diets should, among other things, have a low impact on the environment, be protective and respectful to biodiversity and ecosystems and optimise natural resources use.

This paper aims at analysing the main environmental impacts of the Mediterranean food consumption patterns on land and water resources and biodiversity.

\section{Materials and Methods}

The paper provides a review on water and land resources and biodiversity in the Mediterranean and an analysis of the livestock sector impacts on ecosystem services. The most recent FAO food consumption statistics and standard impact data from different sources (e.g., Water Footprint Network; Barilla Centre; Mekonnen \& Hoekstra [12, 13]; Ewing et al. [14, 15]) were used to characterise the Mediterranean food consumption patterns and to calculate and discuss their environmental impacts, i.e., water, carbon, and ecological footprints.

Ehrlich and Holdren [16] decomposed the anthropogenic driving forces of natural capital appropriation into three variables: population, affluence, and technology. This model came to be known as the IPAT model: environmental impact = population $\times$ affluence $\times$ technology. It remains a useful framework for examining environmental impact. Diets can have a direct impact on consumption per person or affluence that's to say calories per person and also types of products and foods that are consumed to meet needs. Moreover, diets can have an indirect impact on footprints since consumer preferences and 
consumption behaviours, via demand and market pull, can influence production methods, technologies, and systems (e.g., organic, conventional, intensive, industrialised agriculture, fishing, aquaculture, intensive/extensive animal husbandry, etc.) and transportation and distribution patterns therefore natural resources use, waste production and pollution intensity.

In this paper, environmental impacts refer to the ecological footprint (EF), carbon footprint (CF) and water footprint (WF).

According to Schaefer et al. [17], the EF is one of the renewable resources accounting tool that is used to address the underlying issue of sustainable consumption. In fact, the EF has emerged as the world's premier measure of humanity's demand on nature [18]. The EF is a method to answer the following research question: How much of the regenerative capacity of the biosphere is occupied by human activities? [17]. Biocapacity refers to the capacity of ecosystems to produce useful biological materials and to absorb waste materials generated by humans, using current management schemes and extraction technologies [18]. The driving forces behind changes in the EF can be derived from the IPAT model. According to Ewing et al. [14], EF $=$ population $\times$ consumption per person $\times$ resource and waste intensity.

The calculation methodology of the EF on a national scale was fully explained by Ewing et al. [14, 15]. The EF measures appropriated biocapacity, expressed in global average bioproductive hectares, across six major land use types (i.e., cropland, grazing land, fishing grounds, forest land, carbon footprint, and built-up land). With the exception of built-up land and forest for carbon dioxide uptake, the EF of each major land use type is calculated by summing the contributions of a variety of specific products. Built-up land reflects the bioproductivity compromised by infrastructure and hydropower. Forest land for carbon dioxide uptake represents the waste absorption of a world average hectare of forest needed to absorb human induced carbon dioxide emissions, after having considered the ocean sequestration capacity. In order to keep track of both the direct and indirect biocapacity needed to support people's consumption patterns, the EF methodology uses a consumer-based approach; for each land use type, the EF of consumption (EFC) is thus calculated as: EFC = EFP + EFI - EFE; where: $\mathrm{EFP}$ is the EF of production; EFI and EFE are the ecological footprints embodied in imported and exported commodity flows, respectively. The EF assessments aim at measuring demand for biocapacity by final demand, but the EF is tallied at the point of primary harvest or carbon emission. Thus, tracking the embodied EF in derived products is central to the task of assigning the EF of production to the end uses it serves. Primary and derived goods are related by product specific extraction rates.

The CF is a measure of the exclusive total amount of $\mathrm{CO}_{2}$ emission that's directly and indirectly caused by an activity or is accumulated over the life stages of a product [19].

The WF is the demand of freshwater resources required to produce goods and services and it represents a measure of human's appropriation of freshwater resources: freshwater appropriation is measured in terms of water volumes consumed (evaporated or incorporated into a product) or polluted per unit of time [20]. The water footprint concept is closely linked to the virtual water concept [21]. The water footprint of a product is similar to what has been called alternatively the "virtual-water content" of the product or the product's embedded, embodied, exogenous or shadow water [22]. The water footprint includes the use of blue water (ground and surface water), green water (rain water or moisture stored in soil strata), and grey water. The grey water footprint refers to pollution and is defined as the volume of freshwater that is required to assimilate the load of pollutants given natural background concentrations and existing ambient water quality standards [23]. The WF is a geographically explicit indicator, showing not 
only volumes of water consumption and pollution, but also the locations. The framework for national water footprint accounting was presented by Hoekstra et al. [23]. The methodology of the global standard for water footprint assessment developed by the water footprint network is set out in the water footprint assessment manual by Hoekstra et al. [23]. The study quantified and mapped the water footprints of nations from both a production and consumption perspective and estimates international virtual water flows, national and global water savings as a result of trade. The entire estimate included a breakdown of water footprints, virtual water flows and water savings into their green, blue and grey components.

In order to characterise diets in Mediterranean countries, especially in terms of dietary energy and share of dietary components, FAO data [24] have been used. An indicator called "share of plant-based energy in the diet" has been considered as the share of energy from cereals, vegetable oils (including olive oil), roots and tubers, fruits (excluding wine and vegetables) and pulses.

Differences in terms of plant-based energy and environmental impacts between North Africa (Algeria, Libya, Morocco, Tunisia), Middle East (Egypt, Jordan, Lebanon, occupied Palestinian territory, Syria, Turkey), the Balkans (Albania, Bosnia and Herzegovina, Croatia, Macedonia), the North Mediterranean (Cyprus, France, Greece, Italy, Malta, Portugal, Slovenia, Spain), Asia (China, India, Japan), Australia, Central and Northern Europe (Austria, Belarus, Belgium, Denmark, Estonia, Finland, Germany, Iceland, Ireland, United Kingdom), Latin America (Argentina, Brazil), North America (Canada, United States of America) have been analysed.

\section{Results and Discussion}

\subsection{Water Resources in Mediterranean Countries}

In the Mediterranean region, water resources are limited, fragile and unevenly distributed over space and time. Southern rim countries are endowed with only
$13 \%$ of the total resources [25]. Irrigation accounts for almost $65 \%$ of anthropogenic abstraction in the Mediterranean. It may even exceed $80 \%$ in the southern and eastern Mediterranean countries [26]. The seasonal nature of rainfall plays a crucial role in water stress as agronomic water demand of some Mediterranean crops coincides with the periods of the lowest rainfall and water availability [27].

According to the projections of the blue plan baseline scenario and compared to the year 2000, water demands may increase by a further $15 \%$ by 2025 , especially in the southern and eastern countries where are expected an increase of 25\%. Furthermore, Mariotti et al. [28] predicted by 2070-2099 an average decrease of $20 \%$ in surface water availability, with a decrease in soil moisture and river runoff, and a $24 \%$ increase in the loss of fresh water over the Mediterranean due to precipitation reduction and warming-enhanced evaporation. In fact, the impact of climate change on the Mediterranean environment is already noticeable [29]. Thus, improving the water demand management, water saving and rational water use, especially for agriculture, is of a paramount importance in the Mediterranean region. In fact, estimated total water use efficiency for the Mediterranean countries ranges between $50 \%$ and $85 \%$ [26]. Water demand management measures may free up significant amounts of water. They are economically worthwhile if they allow to maintain water supply when it is a limiting factor. The market may create a preference for crops which consume less amounts of water. However, incentives and regulatory measures are also to be explored [27].

The various occurrences of land degradation, particularly erosion, are as old as the region [30]. Moreover in modern times new threats have appeared, which are linked to the social and economic upheavals of recent years; poorly done modern farming intensification in certain sectors; encroachment on space by urbanisation and infrastructures; urban and industrial waste pollution etc.. 


\subsection{Plants and Crops Diversity in the Mediterranean}

3.2.1 Biodiversity in the Mediterranean Hotspot

It is clear that we are in an era of unprecedented threats to biodiversity. 15 out of 24 ecosystem services are assessed to be in decline [31]. The genetic diversification of food crops and animal breeds is diminishing rapidly. In fact, at the beginning of the 21st century, it is estimated that only $10 \%$ of the variety of crops that have been cultivated in the past are still being farmed, with many local varieties being replaced by a small number of improved non-native varieties [32]. Only about 30 crop species provide $95 \%$ of food energy in the world while 7000 species, that are partly or fully domesticated, have been known to be used in food including many of the so-called underutilised, neglected or minor crops [33].

The Mediterranean basin biodiversity hotspot (MBH) is the second largest hotspot in the world. The hotspot covers more than 2 million square kilometres and stretches West to East from Portugal to Jordan and North to South from Northern Italy to Cape Verde. It is one of the greatest areas for endemic plants on Earth and includes several epicentres of plant diversity. Two main circumstances have contributed to the high diversity of the MBH: (i) its location at the intersection of two major landmasses (Eurasia and Africa) and (ii) huge topographical diversity and altitudinal differences. Its climate is unique but rainfall ranges between 100 $\mathrm{mm}$ and $3,000 \mathrm{~mm}$, resulting in high vegetation diversity within the region. These combined factors make the $\mathrm{MBH}$ the third richest hotspot in the world in terms of its plant biodiversity [34]. Approximately 30,000 plant species occur, and more than 13,000 species are endemic to the hotspot; yet, many more are being discovered every year [35]. The $\mathrm{MBH}$ is a centre of plant endemism, with $10 \%$ of the world's plants found in about $1.6 \%$ of the Earth's surface. The hotspot has roughly the same plant diversity as all of tropical Africa, albeit in a surface area one-fourth the size of sub-Saharan Africa [36]. The Mediterranean forests are diverse and harbours up to 100 different tree species.
Moreover, it is estimated that the Mediterranean sea contains $8 \%$ to $9 \%$ of all marine species in the world [37]. In the Mediterranean basin, there is a huge topographic, climactic and geographic variability giving rise to an astounding array of species and habitats diversity. The World Wide Fund for Nature (WWF) has listed 32 eco-regions occurring in the Mediterranean hotspot. There are three broad vegetation types: maquis, forests, and garrigue [36]. Nowadays, the most widespread vegetation type is the maquis. Many of the endemic and restricted-range plants depend on this habitat, and several species are, thus, threatened [38].

\subsubsection{Crops Diversity in the Mediterranean}

Regarding crop diversity, the importance of the Mediterranean can be judged by the fact that about a third of the foodstuff that is used by humankind comes from the Mediterranean climatic region, if not strictly from the topographic basin proper [39]. Barley, wheat, oat, olives, grapes, almonds, figs, dates, peas and other innumerable fruit, vegetables and medicinal or aromatic herbs are derived from wild plants found in the Mediterranean region [37].

The Mediterranean basin was one of the eight centres of cultivated plant origin and diversity identified by Vavilov [40]. Vavilov listed over 80 crops but the most important of these were cereals, pulses, fruit trees and vegetables. There were also many herbs, spice-producing plants, horticultural crops, and ornamentals [41]. Several socio-political, agro-climatic, ecological and genetic factors have contributed to this remarkable crop diversity in the Mediterranean [42].

Agricultural lands and grasslands occupy $40 \%$ of the Mediterranean region and vary between large intensive olive or citrus groves and more mixed farming systems [43]. The low intensity and localised nature of thousands of years of subsistence farming activities has had a profound effect on the landscape, creating a complex mosaic of alternating semi-natural habitats rich in wildlife. Vineyards and ancient olive groves are also still a characteristic feature of the Mediterranean 
landscape. On flatter land and in the plains various forms of sustainable agro-sylvo-pastoral farming systems have evolved to make best use of natural resources [37].

However, whilst small-scale farming is still practiced in many parts of the region, the last 50 years have seen a massive change in agricultural practices across large parts of the Mediterranean. Ancient vineyards, orchards and olive groves have been ripped out to make way for industrial scale fruit or olive plantations, and mixed rotational farming has been replaced by intensive monocultures. This has caused the loss of wildlife-rich habitats [37].

Modern farming practices through their high demand for pesticides, fertilisers and irrigation water put an excessive pressure on the environment. More than 26 million hectares (ha) of farmland is now under irrigation in the Mediterranean basin and in some areas up to $80 \%$ of the available water is used for irrigation. The rapid growth in tourism and urban development in coastal areas combined with the abandonment of small-scale farming practices puts immense pressure on the Mediterranean region's rich biodiversity [37].

\subsection{Mediterranean Food Consumption Patterns}

3.3.1 Characterisation of Mediterranean Food Consumption Patterns

According to FAOSTAT data [24], in Mediterranean countries dietary energy ranges from 2,176 in the occupied Palestinian territory (OPT) to 3,694 $\mathrm{cal} /$ day/person in Greece. In general, dietary energy is higher in northern Mediterranean countries with respect to Eastern and Southern Mediterranean ones.

The share of plant-based energy in the diet in Mediterranean countries ranges from $80.7 \%$ in Egypt to $46.6 \%$ in Cyprus. In general, that share is higher than those obtained in Northern and central European countries (e.g., Germany, Iceland, Denmark, etc.) and North American ones (e.g., USA). The largest share of this plant-based energy is derived from cereals. In fact, out of total dietary energy, from $21.5 \%$ in Spain to
63.7\% in Egypt is derived from cereals. In general, the contribution of plant-based energy to the total dietary energy is higher in Eastern and Southern Mediterranean countries with respect to Northern ones while intermediate values are recorded in Balkan countries. The share of plant-based energy in the Mediterranean diets is higher than $50 \%$ except in France (47.0\%) and Cyprus (46.6\%).

Worldwide, and to certain extent also in the Mediterranean, there is a nutrition transition that is characterised by [32]: a decline in the consumption of traditional staple food and other traditional food crops; an increase in intakes of fat, sugar, and animal foods; an increase in alcohol consumption; an increase in refined and processed foods consumption; and an overall reduction in dietary diversity. In the Mediterranean region also there have been unprecedented changes in lifestyles and food consumption patterns during the past few decades. Diet change is the result of the dual phenomenon of the spread of the English-speaking countries dietary model and of globalization [44].

3.3.2 Diversity of Plants Consumed in the Mediterranean

The Mediterranean region has been created over centuries a diet that is unique in its tremendous diversity. It is mainly the result of a mosaic of peoples and cultures in the region. The blending that has been taking place between Mediterranean people, cultures and civilisations has broaden dietary and culinary repertoires [44]. The most important factors that contributed to this huge diversity of foods and diets in the Mediterranean were: extremely varied geographical and ecological environments; succession of different dominant peoples that introduced and/or diffused different crops and foods; essential role played by ports and to a certain extent also by big towns in intermixing cultures thus food patterns [44].

Mediterranean food consumption cultures use different types of cultivated and spontaneous plants thus promoting biodiversity use and conservation. 
Mediterranean diets are far from homogeneous; they involve a wealth of typical products and they are extremely varied. It is that diversity which provides a certain level of nutritional and social well-being for the various populations [44]. The general term "Mediterranean diet" inevitably implies a common dietary scheme in Mediterranean countries. However, this is not the case since differences in dietary patterns of the Mediterranean populations are evident (e.g., Trichopoulou \& Lagiou, 1997 [45]). This “dietary polymorphism” partially reflects religious and cultural differences [46]. It is noteworthy, that even within the same country, significant dietary differences can be seen. In Italy, for instance, cereals, fruit, and vegetables consumption is higher in the Southern part of the country [47].

In many rural regions, especially of Southern and Eastern Europe, non-cultivated food plants are still gathered [48]. Local foods represent a type of mutual interactions between the availability of locally growing and edible plants, and the nutritional requirements and needs of populations. In general, wild varieties tend to be richer in micronutrients and bioactive secondary metabolites than cultivated ones. Such secondary plant metabolites are produced in adaptation to local environmental conditions [11]. The diversity of local Mediterranean food elements is not well known. Edible wild plants and weeds are interesting local elements in Mediterranean food cultures. Ethnobotanical research has identified about 2,300 different plant and fungi taxa which are gathered and consumed in the Mediterranean [49]. The percentage of local gathered food plant (GFP) taxa, is higher in the main diversity centres at the periphery of the Mediterranean (Sahara, Alps, Caucasus, Canary Islands, the Levant) and islands (Sicily, Sardinia, Crete, Cyprus). Bonet and Vallès [50], in an ethnobotanical survey carried out in the massif of Montseny (Catalonia, Spain), recorded the consumption of 132 GFP taxa. As for North Africa, Gast [51] exhaustively reported on 80 species of wild vegetables and grains food plants used by Berber groups during the famine season (December to March) in the Ahaggar region (Algeria).

In Italy, 880 gathered food plants are consumed [52]. Sardinia has the highest proportion of GFPs, 257 taxa for about 2,100 in the vascular plant flora [53]. A recent research showed that 532 species of herbaceous wild edible plants are consumed in Apulia region (South-Eastern Italy) out of 2,500 representing the flora of the region. Out of these 532 species, 104 belong to the Asteraceae family and there are 44 Lamiacee, 40 Brassicaceae, 38 Fabaceae, and 29 Amaranthaceae and Apiaceae. As for genera, they are 304 and the most important ones are: Allium (12), Chenopodium (10), Vicia and Rumex (9), Amaranthus, Plantago and Crepis (7), and Salvia and Valerianella (6). Domestication of wild species has been never stopped in Italy. In fact, for 122 species of wild edible plants identified in Apulia there have been attempts for growing them in open fields and/or in greenhouses. Among the most successful examples of domestication can be mentioned that of Diplotaxis tenuifolia, whose domestication started 20 years ago, that is now grown on more than 1,000 ha of greenhouses in Italy [52].

\subsection{Main Environmental Impacts of Food Consumption in the Mediterranean}

There are growing evidence on the impact of diet on health, including increased risk of obesity, cardiovascular diseases and cancers, and also of its role as a social indicator $[1,54]$. However, sustainability of the food system and of food consumption is about more than health concerns as it regards also environmental impact. According to one large European study, food and drink accounts for an estimated $20 \%$ to $30 \%$ of the environmental impact of all consumption [55].

The impact on environment is addressed by using the footprint concept involving EF, CF andWF.

3.4.1 Assessment of the Ecological and Carbon Footprints

Elaborated data from the national footprint accounts for statistics of 2007 presented by Ewing et 
al. [14], showing that the Mediterranean EF of consumption are always higher than the EF of production (Fig. 1), except for Serbia. Furthermore, the CF alone is generally higher than the biocapacity, except for Morocco, Tunisia, Albania, Turkey, Bosnia, Croatia, and France. In general, results show that the Northern Mediterranean countries have a high EF, while impact of North Africa and Middle East countries is the lowest.

Referring to the EF of production, the period needed to regenerate the resources used in the year 2007 by Mediterranean countries ranged between 5 years and 5 months, and 1 year and 3 months, respectively in Libya and Albania. While considering the EF of consumption, the period needed to regenerate the resources consumed ranged between 8 years and 6 months, and 1 year and 6 months, respectively in Jordan and Croatia. Thus, the Mediterranean countries have a net demand on the planet greater than their respective biocapacity: as average values, 2 years and 3 months are needed to regenerate the resources used for production, while 3 years and 4 months are needed to regenerate the resources effectively consumed.

Fig. 2 shows that North America has the highest EF, while Asia has a similar EF to North Africa and Middle East. The European countries, including the
Mediterranean ones, have a higher EF with respect to Asia, Oceania, and Latin America.

Taking into consideration land use types (i.e., cropland, grazing land, forest land, fishing grounds, and built-up land), results show that the cropland use type EF is the highest in Mediterranean countries, while the EF of the grazing and forest land is the highest in Oceania (Fig. 3). The average EF in Balkans and North Mediterranean countries is at least 1.5 times the EF of the North Africa and Middle East.

The EF per capita in the Mediterranean region increased in the period 1961-2007 except in Morocco, Jordan and Albania, while the biocapacity decreased. Thus the ecological deficit is going to increase. In average, the EF has increased by $47.4 \%$ while the biocapacity decreased by $36.4 \%$.

Overall agriculture is the largest single source of greenhouse gas emissions in the food chain [56] with meat and meat products being the largest contributor [57]. In addition, food production globally has major implications for biodiversity, including habitat loss, water and land use, and pollution [1]. Despite the fac that data acquired for some foods vary quite significantly, the classification of the impact of individual foods is nonetheless sufficiently clear: red meat is the food with the greatest impact, while fruit and vegetables have a decidedly limited impacts [8]. In

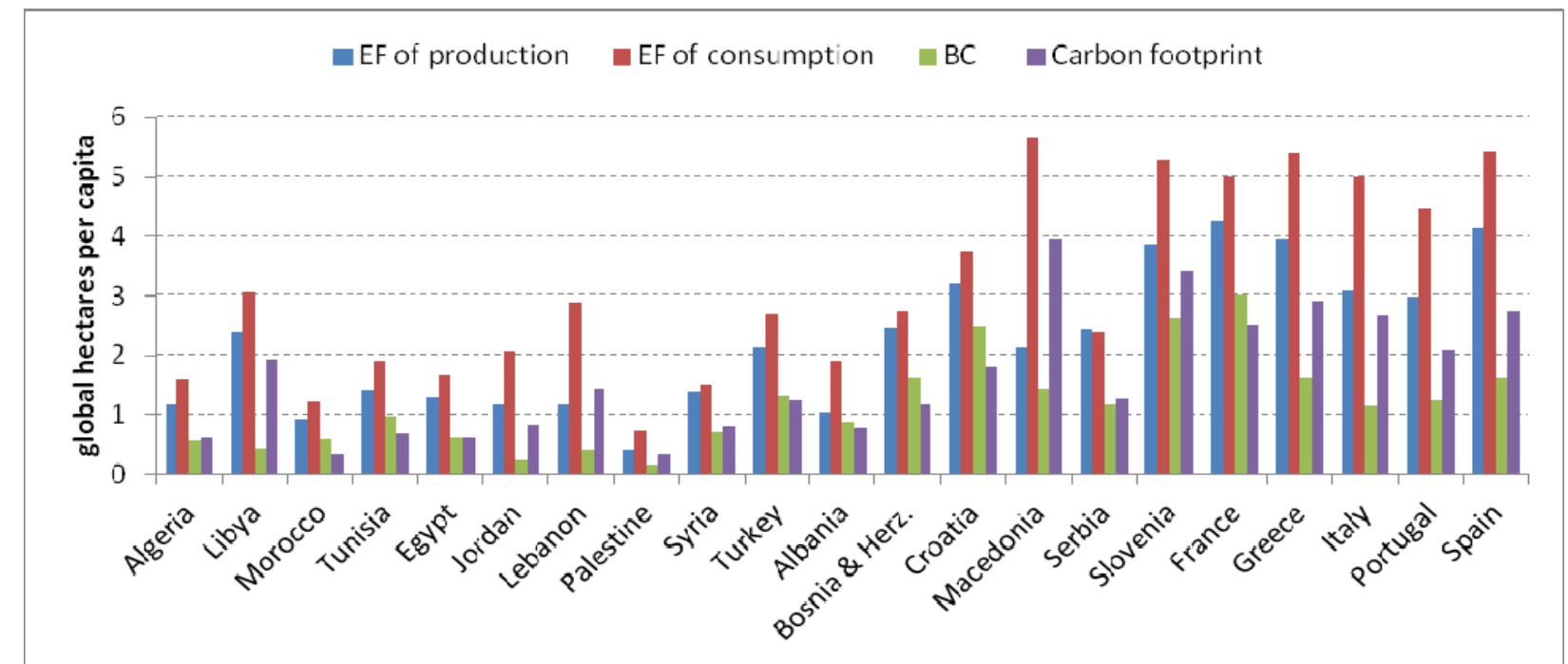

Fig. 1 A comparative analysis of EF of production, EF of consumption, biocapacity, and carbon footprint in the Mediterranean region (Source of data: Ewing et al. [14]). 


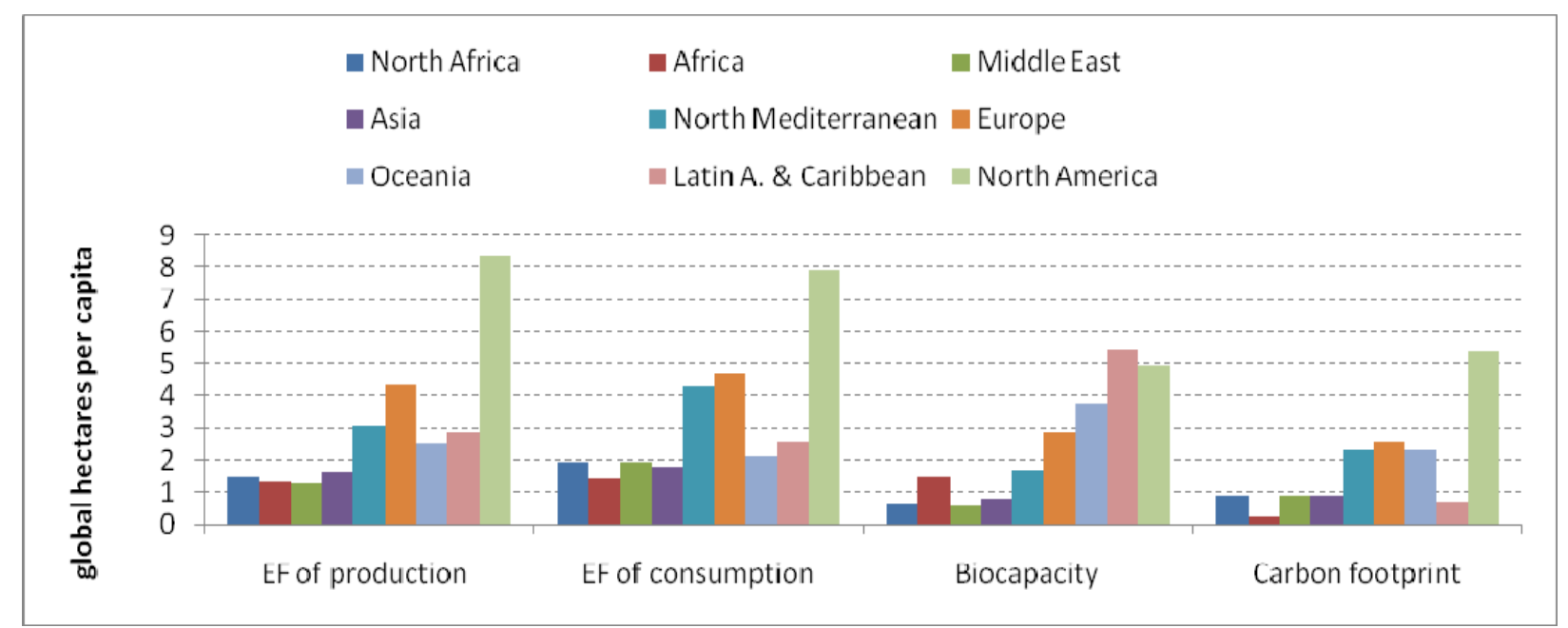

Fig. 2 The Mediterranean region in the world: a comparative analysis in terms of EF of production, EF of consumption, biocapacity, and carbon footprint (Source of data: Ewing et al. [14]).

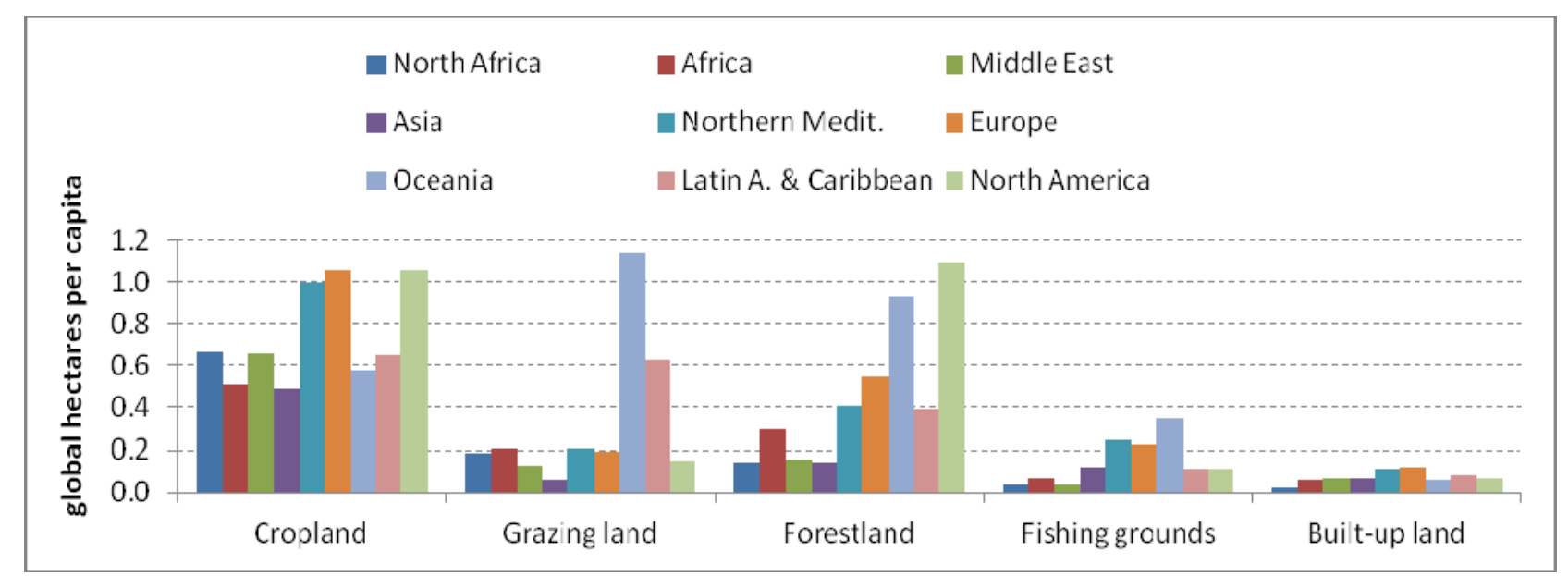

Fig. 3 The Mediterranean in the world: a comparative analysis in terms of EF by land use type (Source of data: Ewing et al. [14]).

general, the lower the animal consumption is (especially beef meat), the lower the environmental is impacted.

Meat production has a higher environmental impact than fruit and vegetables production. The global livestock sector contributes about $40 \%$ to global agricultural output. Meat and dairy animals now account for about $20 \%$ of all terrestrial animal biomass [31].

The livestock sector is considered as one of the major players in the reduction of biodiversity since it is one of the most important drivers of deforestation, land degradation, pollution, climate change, erosion and sedimentation of coastal areas, facilitation of alien species invasion, among others [31]. 306 of the 825 terrestrial eco-regions identified by the WWF reported livestock as one of the current threats. Twenty-three of 35 global hotspots for biodiversity identified by conservation international are reported to be affected by livestock production. An analysis of the red list of threatened species, of the World Conservation Union (IUCN), shows that most of the world's threatened species are suffering habitat loss where livestock are a factor [58]. The environmental impacts of animal production vary with the method of production (e.g., extensive grazing, grazing-based production, etc.) [59].

Nowadays, a large proportion of crops are not consumed directly by people but indirectly as meat, 
milk and dairy products with vast quantities of grains grown only to be used as animal fodder. This may be economically efficient but it is not efficient from the nutritional and mainly from the ecological points of view [32]. The amount of cereals used today for feed varies between regions, ranging from $20 \%$ in sub-Saharan Africa to 70\% in OECD countries [60].

According to the Livestock, Environment and Development (LEAD) initiative, the livestock industry is one of the largest contributors to environmental degradation, at local and global scale, contributing to deforestation, air and water pollution, land degradation, loss of topsoil, climate change, the overuse of resources including oil and water, and loss of biodiversity. The use of large industrial monoculture, common for feed crops (e.g., corn and soya), is highly damaging to ecosystems. The initiative concluded that the livestock sector emerged as one of the most significant contributors to the most serious environmental problems [31].

According to studies carried out by the EU's Environmental Impact of Products (EIPRO), the production and consumption of food accounts for $22 \%-31 \%$ of the EU countries' total greenhouse gas (GHG) emissions-the so-called food's carbon footprint. The consumption of meat and dairy products is estimated to be responsible for approximately $14 \%$ of Europe's overall impact on global warming [61]. As matter of fact, EIPRO showed that food and drink are responsible for $20 \%-30 \%$ of the various environmental impacts (i.e., abiotic depletion, acidification, ecotoxicity, global warming, eutrophication, human toxicity, ozone layer depletion and photochemical oxidation) of total consumption, and in the case of eutrophication for even more than 50\%. Within this area of consumption, meat and meat products (including meat, poultry, sausages, etc.) have the greatest environmental impact and their estimated contribution to global warming is in the range of $4 \%$ to $12 \%$ of all products. The second important product grouping in terms of environmental impacts is dairy products [61]. A smaller carbon footprint stems from plant-based foods such as outdoor vegetables, flour, grains and bread. Outdoor grown vegetables have the lowest climate impact per kg of produce [59].

Steinfeld et al. [31] estimated that $18 \%$ of annual worldwide GHG emissions are attributable to cattle, buffalo, sheep, goats, camels, pigs, and poultry. However, recent analysis by Goodland and Anhang [62] finds that livestock and their by-products actually account for at least 32.6 billion tons of carbon dioxide per year, or $51 \%$ of annual worldwide GHG emissions.

\subsubsection{Assessment of the Water Footprint}

The global freshwater resources are subject to increasing pressure in the form of consumptive water use and pollution [63, 64]. The increase in water needed to meet the demand for food is a major concern given the growing water scarcity and environmental problems. Already 1.4 billion people live in places where water is physically scarce [65]. The Comprehensive Assessment of Water Management in Agriculture [65] estimated that water demands could double with present production practices by the year 2050. What kind of food is demanded and how much, determine to a large extent how water for agriculture is allocated and used [60].

Food supply directly translates into consumptive water use, that is, how much water is transpired and evaporated from the field during the production of a specific amount of food [66]. Water requirements for plant and animal products vary widely. Higher value crops (e.g., horticultural crops) typically require more water per calorie than staple cereal crops. Meat and dairy production is more water-intensive than crop production. In fact, 500-4,000 litres of water are evaporated in producing one kilogram of wheat; depending on many factors (e.g., climate, agricultural practices, variety, growing season length, yield). However, to produce one kilogram of meat takes 5,000-20,000 litres, mainly to grow animal feed. In terms of the energy content of food, approximately 0.5 $\mathrm{m}^{3}$ of water is needed to produce $1,000 \mathrm{kcal}$ of 
plant-based food, while for animal-based food, some 4 $\mathrm{m}^{3}$ of water are required. Assuming a projected high level of average food supply of 3,000 kcal/capita/day, with $20 \%$ animal and $80 \%$ plant food, the consumptive water use will be above $3 \mathrm{~m}^{3} /$ capita/day-1,300 $\mathrm{m}^{3} /$ capita/year [67].

According to Mekonnen and Hoekstra [20], the global water footprint was $9087 \mathrm{Gm}^{3} / \mathrm{yr}$ (74\% green, $11 \%$ blue, $15 \%$ grey) in the period 1996-2005 and agricultural production contributes $92 \%$ to this total footprint. The total volume of international virtual water flows related to trade in agricultural and industrial products is 2320 $\mathrm{Gm}^{3} \mathrm{yr}^{-1}$ (68\% green, $13 \%$ blue, $19 \%$ grey) of which $76 \%$ is related to crop products trade (animal products trade contributes $12 \%)$. Moreover, the water footprint of the global average consumer was $1,385 \mathrm{~m}^{3} / \mathrm{yr}$ in the period 1996-2005, of which $92 \%$ is related to agricultural products consumption.

Elaborated data from of the period 1996-2005 show a high variation of the WF of consumption between Mediterranean countries (Fig. 4), especially in terms of internal and external WF of consumption. In fact, percentage of the external WF of consumption varies between $7.3 \%$ and $85.8 \%$, respectively in Palestine and Jordan. Countries of the North Mediterranean had the highest WF of consumption per year and per capita $\left(2,279 \mathrm{~m}^{3}\right)$ compared to North Africa $\left(1,892 \mathrm{~m}^{3}\right)$, Balkans $\left(1,708 \mathrm{~m}^{3}\right)$ and Middle East $\left(1,656 \mathrm{~m}^{3}\right)$.

Most of the WF of consumption is in fact due to agricultural products consumption, as shown in Fig. 5. The observed average value is about $91 \%$ of the total WF of consumption: 96\% in North Africa, 93\% in Middle East, $82 \%$ in Balkans, and 91\% in northern Mediterranean countries.

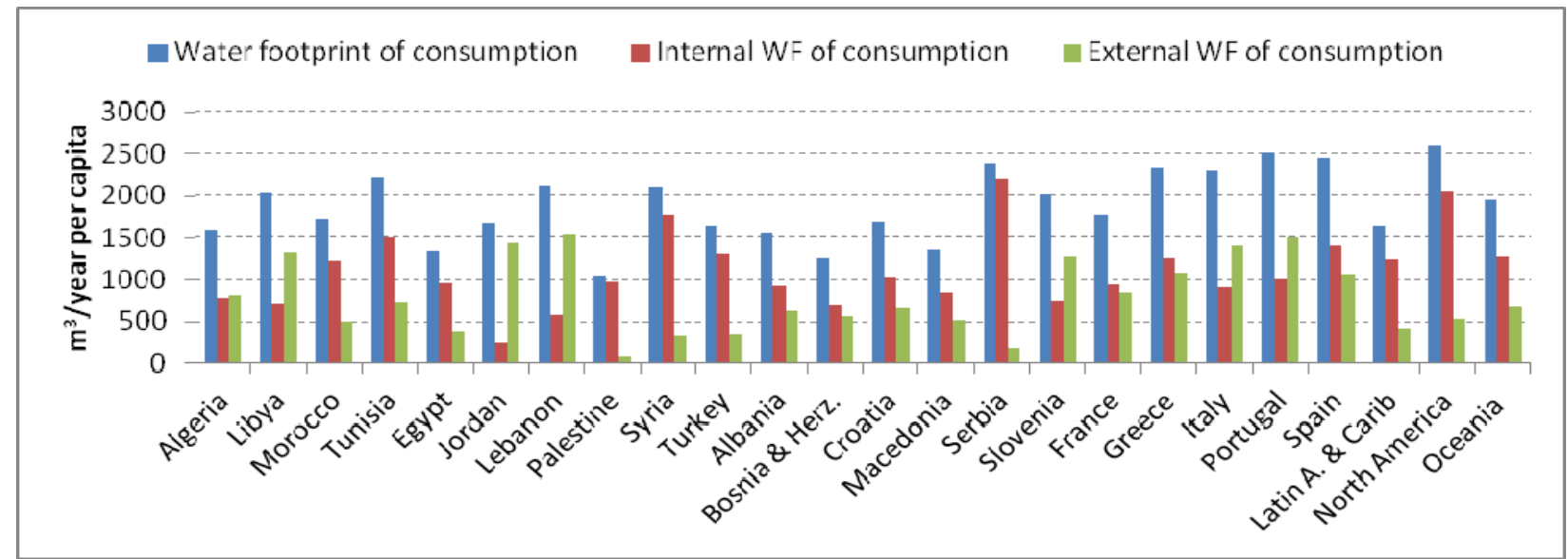

Fig. 4 Water footprint of consumption (Source of data: Mekonnen and Hoekstra [20]).

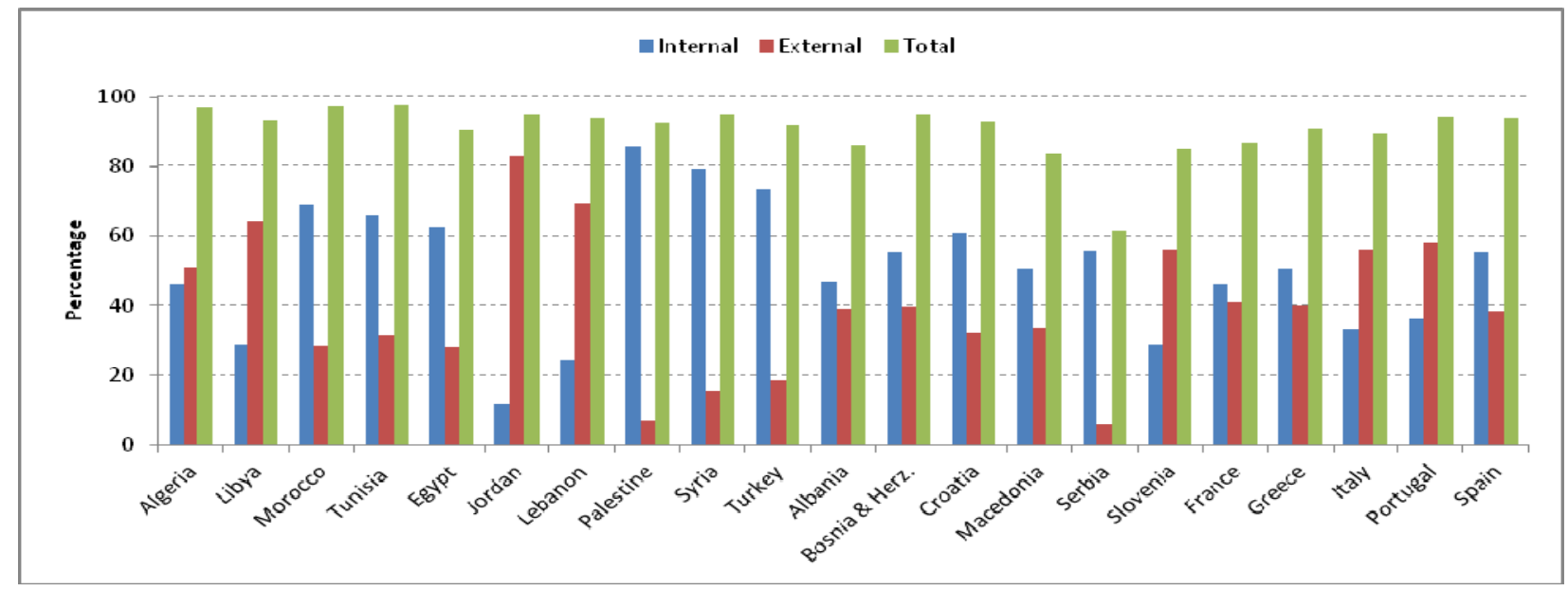

Fig. 5 WF of agricultural products consumption (Source of data: Mekonnen and Hoekstra [20]). 
The study of Mekonnen and Hoekstra [20] evaluated also the net virtual water import between the years 1995 and 2005 (Table 1) as an indicator of the water saving as a result of trade in agricultural products. Only Tunisia, Syria and Serbia present a negative total net virtual water import/export. Thus, the other Mediterranean countries show a water saving ranging between 340 and 62,157 $\mathrm{Mm}^{3}$ in Macedonia and Italy, respectively. In the Mediterranean region, a total of water saving of $177,168 \mathrm{Mm}^{3}$ (including the three forms of virtual water) is observed.

\section{Conclusions}

Mediterranean food consumption patterns contribute to biodiversity conservation for at least two main reasons. First of all because they promote the use of a wide range cereals, fruits and vegetables, not only cultivated but also spontaneous and wild species, thus allowing their conservation as well as the local, indigenous and traditional knowledge related to these species. Moreover, by using less meat and animal products, Mediterranean diets reduce environmental impacts of livestock sector on biodiversity and natural resources. In fact, "meat-based diets”, as northern ones, have higher environmental impacts (e.g., water footprint, ecological footprint, carbon footprint) than "plant-based diets", such as Mediterranean ones. Moreover, promotion of the use of local and typical products contributes to reducing environmental impacts (food miles and carbon footprint).

Nevertheless, it is necessary to have further studies on environmental impacts and sustainability of Mediterranean food consumption patterns by taking into consideration foods origins, production and distribution systems and methods as well as foods and drinks wastage.

Imports of cereals and high prices put in question the socio-economic and environmental sustainability of the Mediterranean diet especially in some Southern and Eastern Mediterranean countries. High prices of cereals, especially, fruit and vegetables risk to transform the
Table 1 The net virtual water import/export per countries $\left(\mathrm{Mm}^{3}\right.$ year $\left.^{-1}\right)$.

\begin{tabular}{lllll}
\hline Countries & Green & Blue & Grey & $\begin{array}{l}\text { Total (Green } \\
\text { Blue + Grey) }\end{array}$ \\
\hline Algeria & $14,269.8$ & $1,458.5$ & $1,582.6$ & 17,311 \\
Libya & $6,846.5$ & $1,553.1$ & $1,159.8$ & 9,559 \\
Morocco & $8,513.1$ & $-1,301.4$ & $1,124.8$ & 8,337 \\
Tunisia & $-2,829.9$ & 995.5 & 168.2 & $-1,666$ \\
Egypt & 14,661 & $-5,445.9$ & -164.3 & 9,051 \\
Jordan & $4,341.3$ & 645.1 & 680.2 & 5,667 \\
Lebanon & $2,965.9$ & 517 & 574.3 & 4,057 \\
Palestine & - & - & - & - \\
Syria & 575.2 & $-2,494.5$ & -347.5 & $-2,267$ \\
Turkey & $8,577.2$ & $-4,658.1$ & $1,866.8$ & 5,786 \\
Albania & 835.1 & 174.7 & 154.8 & 1,165 \\
Bosnia and & $1,318.3$ & 116.6 & 455.7 & 1,891 \\
Herzegovina & & & \\
Croatia & $1,203.6$ & 199.5 & 570.3 & 1,973 \\
Macedonia & 428.9 & 10.6 & -99.5 & 340 \\
Serbia & 167.1 & 87.8 & $-2,034.6$ & $-1,780$ \\
Slovenia & $1,308.7$ & 202.1 & -95.8 & 1,415 \\
France & 6,658 & $3,029.4$ & $3,134.9$ & 12,822 \\
Greece & $5,458.7$ & -870.2 & 2,314 & 6,903 \\
Italy & $49,388.4$ & $6,278.3$ & 6,490 & 62,157 \\
Portugal & $8,674.9$ & 749.6 & 821.3 & 10,246 \\
Spain & $21,386.1$ & $-3,295.1$ & $6,111.8$ & 24,203 \\
Canada & $-46,720$ & $1,484.2$ & $-7,341.1$ & $-52,577$ \\
USA & $-80,701$ & $-8,805$ & 9,926 & $-79,580$ \\
\hline & & & & \\
\hline
\end{tabular}

traditional MD into a diet of only rich Mediterranean people. Moreover, population increase, especially in Southern and Eastern Mediterranean countries, will increase pressure on the limited and scarce Mediterranean natural resources in particular water. In fact, almost $65 \%$ of water resources in the Mediterranean are used in irrigation. This puts under question also the sustainability of a diet that is based, also, on irrigated crops such as vegetables and fruit. In general, the EF per capita in the Mediterranean in the period 1961-2007 increased (+47.4\%) while the biocapacity decreased (-36.4\%) causing an increase of the ecological deficit. Furthermore, the carbon footprint is generally higher than the biocapacity especially in northern Mediterranean countries. Agriculture, especially intensive irrigated agriculture, has also a negative impact on biodiversity. 
In addition, not only food production but also food transportation, distribution, consumption as well as waste management are all issues that have to be addressed properly in order to improve the sustainability of Mediterranean food consumption patterns.

All in all, promotion of Mediterranean diets can contribute to sustainable land and water resources management and biodiversity conservation but it is not enough therefore strategies and policies should be designed and implemented with the active involvement and participation of all relevant stakeholders, especially, smallholders who are the main biodiversity custodians, natural resources direct managers, biodiversity, water and land resources-related local knowledge repository.

\section{References}

[1] S. Reddy, T. Lang, S. Dibb, Setting the Table-Advice to Government on priority elements of sustainable diets, Sustainable Development Commission, UK, 2009.

[2] FAO, Biodiversity in Sustainable Diets, Report of a Technical Workshop, Rome, May 31-June 1, 2010, FAO, Rome, 2010.

[3] C. Lacirignola, R. Capone, Mediterranean Diet: Territorial identity and food safety, New Medit, No.1, 2010.

[4] K. Esposito, D. Giugliano, Diet and inflammation: A link to metabolic and cardiovascular diseases, European Heart Journal 27 (2006) 15-20.

[5] E.J. Brunner, A. Mosdol, D.R. Witte, Dietary patterns and 15-y risks of major coronary events, diabetes, and mortality, American Journal of Clinical Nutrition 87 (2008) 14-21.

[6] F. Sofi, F. Cesari, R. Abbate, G.F. Gensini, A. Casini, Adherence to Mediterranean diet and health status: meta-analysis, British medical journal 337 (2008) 1344.

[7] D. Giugliano, K. Esposito, Mediterranean diet and metabolic diseases, Current Opinion in Lipidology 19 (2008) 63-68.

[8] Barilla Center, Double pyramid: healthy food for people sustainable food the planet [Online], 2010, Barilla Center for Food \& Nutrition, Parma, Italy, http://www.barillacfn.com/uploads/file/72/1277731651_P ositionPaper-BarillaCFN_Doppia-Piramide.pdf.

[9] A. Keys, Coronary heart disease in seven countries, Circulation 41 (1970) 1-21.

[10] A. Naska, Mediterranean diet at present, in: S. Barnat (Ed.), International Conference on Health Benefits of Mediterranean Diet, Abstract Book, Aghia Pelagia, EGEA,
2003, p. 21.

[11] M. Heinrich, W.E. Müller, C. Galli, Local Mediterranean Food Plants and Nutraceuticals, Karger, Basel, 2006.

[12] M.M. Mekonnen, A.Y. Hoekstra, The green, blue and grey water footprint of crops and derived crop products, Value of Water Research Report Series No. 47, UNESCO-IHE, Delft, the Netherlands, 2010.

[13] M.M. Mekonnen, A.Y. Hoekstra, The green, blue and grey water footprint of farm animals and animal products, Value of Water Research Report Series No.48, UNESCO-IHE, Delft, the Netherlands, 2010.

[14] B. Ewing, D. Moore, S. Goldfinger, A. Oursler, A. Reed, M. Wackernagel, The Ecological Footprint Atlas 2010, Global Footprint Network, Oakland, 2010, p. 113.

[15] B. Ewing, A. Reed, A. Galli, J. Kitzes, M. Wackernagel, Calculation Methodology for the National Footprint Accounts, 2010 Edition, Oakland: Global Footprint Network, 2010.

[16] P.R. Ehrlich, J.P. Holdren, Impact of population growth, Science New Series 171 (3977) (1971) 1212-1217.

[17] F. Schaefer, U. Luksch, N. Steinbach, J. Cabeça, J. Hanauer, Ecological footprint and biocapacity: the world's ability to regenerate resources and absorb waste in a limited time period. Working papers and studies, European Commission, 2006, ISBN 92-79-02943-6.

[18] GFN, Footprint Basics Overview, Global Footprint Network (GFN) [Oline], 2011, http://www.footprintnetwork.org/en/index.php/GFN/page /footprint_basics_overview/.

[19] T. Wiedmann, J. Minx, A Definition of "Carbon Footprint”, in: C.C. Pertsova (Ed.), Ecological Economics Research Trends, Nova Science Publishers, Hauppauge NY, USA, Chapter 1, 2008, pp. 1-11.

[20] M.M. Mekonnen, A.Y. Hoekstra, National water footprint accounts: The green, blue and grey water footprint of production and consumption. Value of Water Research Report Series No. 50, United Nations Educational, Scientific and Cultural Organization (UNESCO), Institute for Water Education (IHE), Delft, The Netherlands, 2011.

[21] A.Y. Hoekstra, A.K. Chapagain, Water footprints of nations: Water use by people as a function of their consumption pattern, Water Resources Management 21 (2007) 35-48.

[22] A.Y. Hoekstra, A. K. Chapagain, Globalization of Water: Sharing the Planet's Freshwater Resources, Blackwell Publishing, Oxford, 2008.

[23] A.Y. Hoekstra, A.K. Chapagain, M.M. Aldaya, M.M. Mekonnen, The Water Footprint Assessment Manual: Setting the Global Standard. Water Footprint Network; Earthscan, London \& Washington DC, 2011, p. 224.

[24] FAO, FAO Statistical Yearbook 2009, Consumption, Rome [Oline], 2009, 
http://www.fao.org/economic/ess/publications-studies/sta tistical-yearbook/fao-statistical-yearbook-2009/d-consum ption/en/.

[25] Blue Plan, Facing water stress and shortage in the Mediterranean, Blue Plan notes n4, Environment and Development in the Mediterranean, 2006.

[26] G. Thivet, M. Blinda, Améliorer l'efficience d'utilisation de l'eau pour faire face aux crises et pénuries d'eau en Méditerranée, Plan Bleu, Sophia-Antipolis, 2007, p. 13.

[27] S. Fernandez, A. Mouliérac, Economic evaluation of water demand management in the Mediterranean. Study report, Plan Bleu, Regional Activity Centre of the United Nations Environment Programme (UNEP)/Mediterranean Action Plan (MAP), Sophia Antipolis, Valbonne, France, 2010.

[28] A. Mariotti, N. Zeng, J. Yoon, V. Artale, A. Navarra, P. Alpert, et al., Mediterranean water cycle changes: transition to drier 21st century conditions in observations and CMIP3 simulations, Environmental Research Letters 3 (2008) 8.

[29] Blue Plan, The Blue Plan's Sustainable Development Outlook for the Mediterranean, UNEP Blue Plan Activity Centre, Sophia Antipolis, France, 2008.

[30] Blue Plan, Threats to soils in Mediterranean countries. Document Review, Plan Bleu Papers 2, 2003, ISBN: 2-912081-14-9.

[31] H. Steinfeld, P. Gerber, T. Wassenaar, V. Castel, M. Rosales, C. de Haan, Livestock's long shadow: Environmental issues and options, Food and Agriculture Organization of the United Nations (FAO), Rome, 2006.

[32] E. Millstone, T. Lang, The Atlas of Food. Earthscan, 2nd ed., London, 2008.

[33] J.T. Williams, N. Haq, Global research on underutilised crops: An assessment of current activities and proposals for enhanced cooperation, International Centre for Underutilised Crops, Southampton, UK, 2002.

[34] R.A. Mittermeier, P.R. Gil, M. Hoffmann, J. Pilgrim, T. Brooks, C.G. Mittermeier, et al., Hotspots Revisited: Earth's Biologically Richest and Most Endangered Terrestrial Ecoregions, University of Chicago Press for Conservation International, 2004.

[35] E.A. Radford, G. Catullo, B. de. Montmollin, Important Plant Areas of the south and east Mediterranean region: priority sites for conservation. International Union for Conservation of Nature and Natural Resources (IUCN), Gland, Switzerland and Malaga, Spain, Gland, Switzerland and Malaga, Spain, 2011.

[36] CEPF, Ecosystem Profile, Mediterranean Basin Biodiversity Hotspot, Critical Ecosystem Partnership Fund, 2010.

[37] K. Sundseth, Natura 2000 in the Mediterranean Region, European Commission, Environment Directorate General,
Luxemburg, 2009.

[38] G.M. Tucker, M. Evans, A Conservation Strategy for the Wider Environment, BirdLife Conservation Series 6 (1997) 464.

[39] J.R. Harlan, Agricultural Origins and Crop Domestication in the Mediterranean Region, Diversity 11 (1995) 14-16.

[40] N.J. Vavilov, Phytogeographic basis of plant breeding: The origin, variation, immunity and breeding of cultivated plants, Chronica Bot. 13 (1951) 1-366.

[41] V.H. Heywood, The Mediterranean region: A major centre of plant diversity, in: V.H. Heywood, M. Skoula (Eds.), "Wild food and non-food plants: information networking", Proceedings of the II MEDUSA Regional Workshop (1-3 may 1997, Port El-Kantaoui, Tunisia), Cahiers CIHEAM, Options Méditerranéennes 38, 1998, pp. 5-15.

[42] S. Jana, Factors Contribution to Crop Diversity in the Mediterranean, Diversity, 1995, pp. 11-15,

[43] M. Elloumi, A.M. Jouve, Extraordinary farm diversity, in: International Centre for advanced Mediterranean Agronomic Studies (CIHEAM), Mediterra Atlas: Mediterranean Agriculture, Food, Fisheries and the Rural World, Presses de Sciences Po, Paris, 2010, p. 132.

[44] M. Padilla, Dietary patterns and trends in consumption. In Mediterra 2008: The future of agriculture and food in Mediterranean countries, International centre for advanced Mediterranean studies, Paris, Presses de Sciences Po, 2008, pp. 149-170.

[45] A. Trichopoulou, P. Lagiou, Healthy traditional Mediterranean diet: An expression of culture, history, and lifestyle, Nutr. Rev. 55 (1997) 383-389.

[46] Y. Manios, V. Detopoulou, F. Visioli, C. Galli, Mediterranean diet as a nutrition education and dietary guide: Misconceptions and the neglected role of locally consumed foods and wild green plants, in: M. Heinrich, W.E. Müller, C. Galli (Eds.), Local Mediterranean Food Plants and Nutraceuticals, Karger, Basel, 2006, pp: 154-170.

[47] A. Lupo, Nutrition in general practice in Italy, Am J Clin Nutr 65 (1997) 1963-1966.

[48] M. Heinrich, M. Leonti, S. Nebel, W. Peschel, Local food nutraceuticals: An example of a multidisciplinary research project on local knowledge, J. Pharmacol Physiol. 56 (2005) 5-22.

[49] D. Rivera, C. Obón, M. Heinrich, C. Inocencio, A. Verde, J. Fajardo, Gathered Mediterranean food plants: Ethnobotanical investigations and historical development, in, M. Heinrich, W.E. Müller, C. Galli (Eds.), Local Mediterranean Food Plants and Nutraceuticals, Basel, Karger, Forum Nutr, 2006, pp. 18-74.

[50] M.A. Bonet, J. Vallès, Use of non-crop food vascular plants in Montseny biosphere reserve (Catalonia, Iberian Peninsula), Int. J. Food Sci. Nutr. 53 (2002) 225248. 
[51] M. Gast, Moissons du desert, Utilisation des Resources Naturelles au Sahara Central, Paris, Ibis Press, 2000.

[52] V.V. Bianco, R. Mariani, P. Santamaria, Piante spontanee nella cucina tradizionale molese, Levante editori, Bari, 2009.

[53] A.D. Atzei, Le piante nella tradizione popolare della Sardegna. Sassari, Carlo Delfino Editore, 2003.

[54] S. Hawkesworth, A.D. Dangour, D. Johnston, K. Lock, N. Poole, J. Rushton, et al., Feeding the world healthily: The challenge of measuring the effects of agriculture on health, Philosophical Transactions of the Royal Sociely, Biological Sciences 365 (2010) 3083-3097.

[55] A. Carlsson-Kanyama, M. Pipping Ekstrom, H. Shanahan, Food and life cycle energy inputs: Consequences of diet and ways to increase efficiency, Ecological Economics 44 (2003) 293-307.

[56] A. Carlsson-Kanyama, Climate change and dietary choices: How can emissions of greenhouse gases from food consumption be reduced? Food Policy 23 (1998) 277-293.

[57] R. Sinha, A. Cross, B. Graubard, M. Leitzmann, A. Schatzkin, Meat intake and mortality: A prospective study of over half a million people, Archive of Internal Medicine 169 (6) (2009) 562-571.

[58] J.E.M. Baillie, C. Hilton-Taylor, S.N. Stuart, 2004 red list of threatened species: A global species assessment, World Conservation Union (IUCN), Glan, Switwerland \& Cambridge, UK, 2004.

[59] MFAF-DK, Food's carbon footprint, Ministry of Food, Agriculture and Fisheries, Danemark DK [Online], 2010, http://www.fvm.dk/Foods_Carbon_Footprint.aspx?ID=42 268.
[60] J. Lundqvist, C. de Fraiture, D. Molden, Saving Water: From Field to Fork: Curbing Losses and Wastage in the Food Chain, SIWI Policy Brief, The Stockholm International Water Institute (SIWI), Stockholm, 2008.

[61] EC, Environmental Impact of Products (EIPRO): Analysis of the life cycle environmental impacts related to the final consumption of the EU-25, European Commission (EC), Joint Research Centre (DG JRC), Institute for Prospective Technological Studies (IPTS) \& European Science and Technology Observatory (ESTO), Technical Report EUR 22284 EN, 2006.

[62] R. Goodland, J. Anhang, Livestock and Climate Change, World Watch Magazine, Nov./Dec. 2009 issue, 2009, pp. 10-19.

[63] S.L. Postel, Entering an era of water scarcity: The challenges ahead, Ecological Applications 10 (4) (2000) 941-948.

[64] WWAP, The United Nations world water development, in: Water a Shared Responsibility, World Water Assessment Programme (WWAP), UNESCO Publishing, Paris/Berghahn Books, New York, 2006.

[65] CA, Water for food, water for life: a comprehensive assessment of water management in agriculture, International Water Management Institute, Earthscan, London and Colombo, 2007.

[66] D. Molden, Water for food, water for life: A comprehensive assessment of water management in agriculture, Earthscan Publications, London, IWMI, Colombo, Sri Lanka, 2007, pp. 279-310.

[67] M. Falkenmark, J. Rockström, Balancing water for humans and nature: The new approach in ecohydrology, Earthscan Publications, London, 2004. 